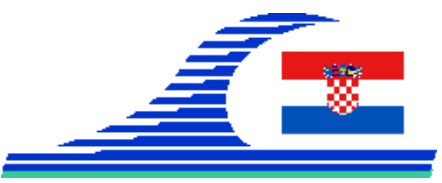

Conférence Méditerranéenne Côtière et Maritime

EDITION 4, SPLIT, CROATIA (2017)

Coastal and Maritime Mediterranean Conference

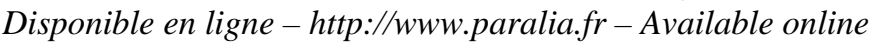

\title{
Coastal water quality and ecological health, enforcement of European policies, monitoring services by EO and crowdsourcing
}

\author{
Antoine MANGIN ${ }^{1}$, Chloé VINCENT ${ }^{1}$, Philippe BRYERE ${ }^{2}$
}

1. ACRI-HE Sophia, 260 route du pin Montard BP 234, 06904 Sophia-Antipolis, France.

antoine.mangin@acri-he.fr,chloe.vincent@acri-he.fr

2. ACRI-HE Brest, bâtiment le Grand Large, $2^{\text {ème }}$ éperon, 29200 Brest, France.

philippe.bryere@acri-he.fr

\begin{abstract}
:
The application of the Water Framework Directive (WFD) or the Marine Strategy Framework Directive (MSFD) of the European Union require a dense and frequent monitoring of chlorophyll-a surface concentration near the coast. To this purpose, the capacity of ocean color imagery from satellite to complete the conventional in situ data set collected in coastal networks have been evaluated. Satellite-derived chlorophyll-a concentration is obtained by the application of the coastal OC5 algorithm at different Instrument Sensor (SeaWiFS, MODIS, MERIS and now Sentinel-3) for the 1998-2017 period. For about 20 years now, satellite-derived and in situ chlorophyll-a concentrations (in situ data of the French monitoring networks Ifremer REPHY and SOMLIT/CNRS) have been compared at more than 20 representative stations of different water bodies. These comparisons show that the satellite products are reliable in most of the situations studied and throughout the seasons. These results have also been confirmed by users of the satellite data operating in the coastal waters of the Northern Western Shelf within MarCoast1\&2 (ESA), ECOOP (UE) ... This article shows different use of the satellite imagery to monitor the chlorophyll-a to classify the coastal waters for the eutrophication risk criterion of the WFD. This classification is made according to the percentile-90 of chlorophyll-a calculated during the productive season. Application of this methodology is also shown for MFSD.
\end{abstract}

\section{Keywords:}

Water Framework Directive, Eutrophication risk, Remote sensing, Chlorophyll-a

\section{Introduction}

The application of the Water Framework Directive (WFD) of the European Union for eutrophication risk criterion require frequent monitoring of chlorophyll-a near the coast. Not counting the transitional water bodies located in the vicinity of estuaries, not less 
Mediterranean rocky coasts:

Features, processes, evolution and problems

than seventy four coastal water bodies have to be monitored along the coast of the French Atlantic continental shelf and the English Channel and about sixty four in Mediterranean Sea. All the available data have to be gathered to implement a comprehensive monitoring scheme. The work presented below has been realized in collaboration with Ifremer Brest and Toulon.

\section{Materials and methods}

To this purpose, the capacity of ocean color imagery to complete the conventional in situ data set collected in coastal networks have been evaluated. Satellite-derived chlorophyll-a concentration is obtained by the application of a coastal Look-Up-Table to water-leaving radiance of the different Instrument Sensor (SeaWiFS, MODIS, VIIRS, MERIS and now Sentinel-3) for the 1998-up to now period. For about 20 years now, satellite-derived and in situ chlorophyll-a concentrations (in situ data of the French monitoring networks Ifremer REPHY and SOMLIT/CNRS) have been compared at more than 20 representative stations of different water bodies (GOHIN et al., 2002; GOHIN, 2011). These comparisons show that the satellite products are reliable in most of the situations studied and throughout the seasons. These results have also been confirmed by users of the satellite data operating in the coastal waters of the Northern Western Shelf within MarCoast1\&2 (ESA), ECOOP (UE) ... Satellite imagery is used here to classify the coastal waters for the eutrophication risk criterion of the WFD. This classification is made according to the percentile-90 (P90) of chlorophyll-a for a period of six years calculated during the productive season, from March to October in Atlantic continental shelf and the English Channel and from January to December in Mediterranean Sea.

\section{Results and discussion}

For the French WFD the first step was to develop methodology to monitor the phytoplankton by satellite imagery which ends in the classification of the French metropolitan water bodies for the risk of eutrophication with remote sensing data (GOHIN et al., 2010). The results show a high consistency with those obtained with in situ data as shows the figure 1 .

So the methodology has been improved along years and applied to ultramarine French territory like French Guyana and Martinique. Since 2015, in collaboration with Ifremer Toulon (LERPAC) ACRI-HE monitors the Mediterranean water bodies for the DCE as shows the figure 2 . 
Mediterranean rocky coasts:

Features, processes, evolution and problems
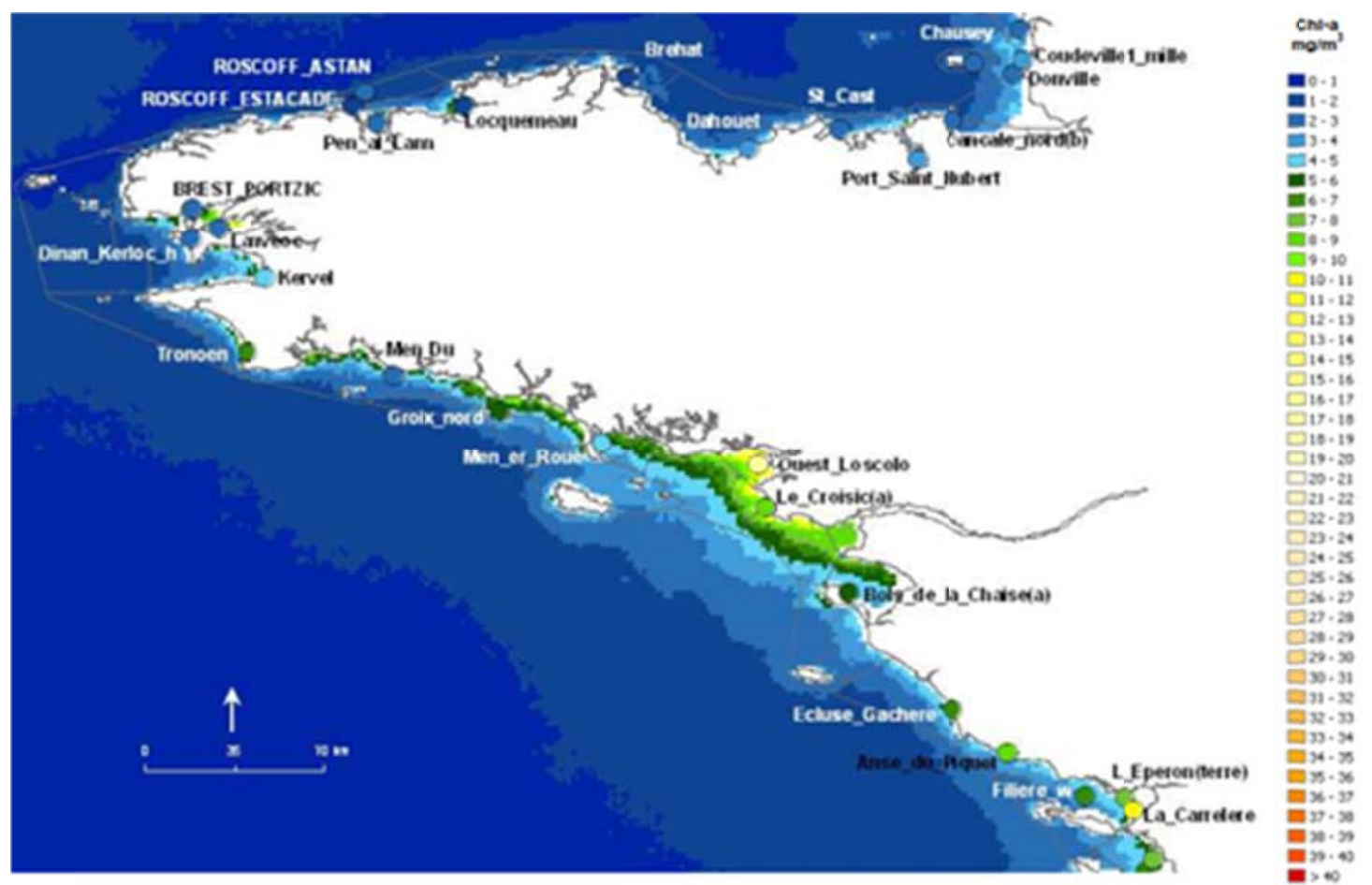

Figure 1. P90 of satellite (MODIS/NASA) chlorophyll-a in French Brittany from2003 to 2008. Filled circle show the in situ P90 for the same period. Grey lines delimit the water bodies of the WFD.

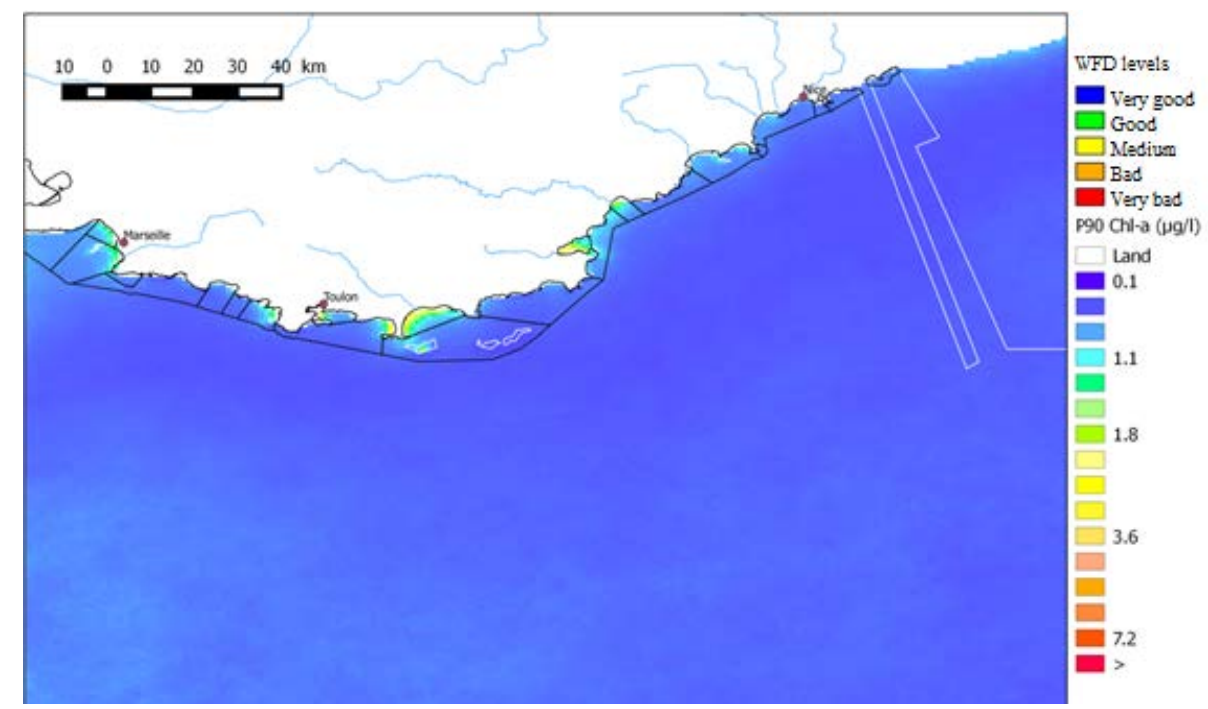

Figure 2. P90 of satellite (MODIS/NASA) chlorophyll-a in French oriental Mediterranean Sea from2010 to 2015. Black lines delimit the water bodies of the WFD, grey lines the MFSD areas.

This methodology developed for the WFD was also applied for the European Marine Strategy Framework Directive (MSFD). So an atlas of the initial states of the 
Mediterranean rocky coasts:

Features, processes, evolution and problems

chlorophyll-a and the sea surface temperature has been done for the French continental shelf and West Europe (GOHIN et al., 2010). In the frame of the MFSD ACRI-HE realises a study, in collaboration with Ifremer Toulon, to map the blooms of primary production with satellite imagery in the French Mediterranean Sea, see figure 3. The aim was to delimit the area for ballast water outside zones and periods of bloom.

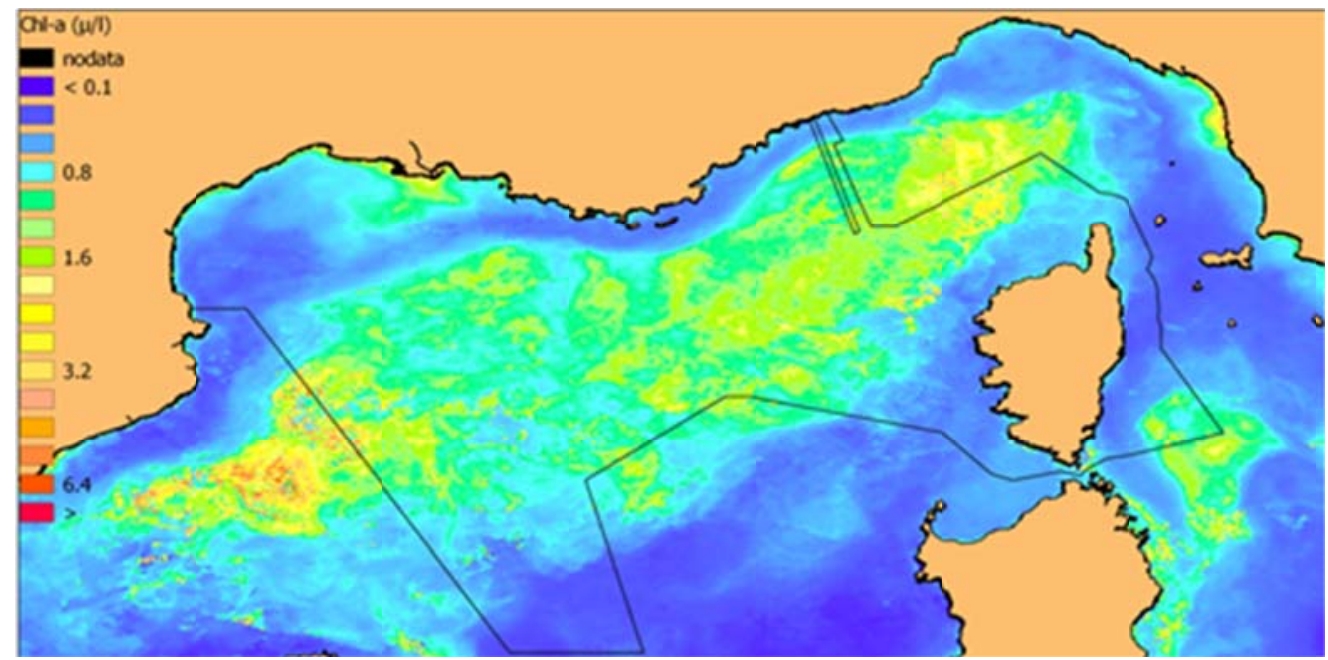

Figure 3. Mean of satellite (MODIS/NASA) chlorophyll-a for April 2010 in Mediterranean Sea. Black lines delimit MFSD areas

\section{Conclusions}

All those examples show that the use of satellite imagery is well adapted to monitor the WFD and the MSFD for the eutrophication risk and the primary production. The best contribution of the satellite is clearly the spatial coverage and the repetitiveness of the observations since about 20 years. New techniques are also entering into force for reporting on invasive species (also part of these directives) and floating and landed macro-wastes. These techniques are using crowdsourcing with dedicated smartphones applications for reporting. This will be presented at the conference.

\section{References}

GOHIN F., DRUON J.N., LAMPERT L. (2002). A five channel chlorophyll concentration algorithm applied to SeaWiFS data processed by SeaDAS in coastal waters. International Journal of Remote Sensing, 23, 1639-1661. doi.org/10.1080/01431160110071879

GOHIN F., SAULQUIN B., BRYERE P. (2010). Atlas de la température, de la concentration en chlorophylle et de la turbidité de surface du plateau continental français et de ses abords de l'Ouest européen. Ifremer. archimer.ifremer.fr/doc/00057/16840/ GOHIN F. (2011). Annual cycles of chlorophyll-a, non-algal suspended particulate matter, and turbidity observed from space and in-situ in coastal waters, Ocean Sci., 7, 705-732, doi:10.5194/os-7-705-2011 